\title{
INTER-PROFESSIONAL EDUCATION IN A CHILD MENTAL HEALTHCARE CONTEXT: CHILDREN'S NURSING AND CLINICAL PSYCHOLOGY STUDENTS LEARNING TOGETHER
}

\begin{tabular}{|r|l|}
\hline Journal: & Journal of Mental Health Training, Education and Practice \\
\hline Manuscript ID & JMHTEP-03-2019-0019.R2 \\
\hline Manuscript Type: & Research Paper \\
\hline Keywords: & Interprofessional, Education, Children's, Nurse, Clinical, Psychology \\
\hline \multicolumn{2}{|r}{} \\
\end{tabular}




\section{INTERPROFESSIONAL EDUCATION IN A CHILD MENTAL HEALTHCARE CONTEXT: CHILDREN'S NURSING AND CLINICAL PSYCHOLOGY STUDENTS LEARNING TOGETHER}

\section{INTRODUCTION}

Interprofessional education (IPE) is said to occur when 'two or more professions learn with, from, and about each other to improve collaboration and the quality of care' (Freeth et al., 2005, p. 11). Four domains are believed to be core to interprofessional education: the ethics and values for inter-professional practice; knowledge and understanding of roles and responsibilities; communication; and collaborative teamwork (DeLeon et al., 2015). Healthcare professionals generally share a desire to provide high quality care for patients, and in providing that care, it is important that they work together to achieve best outcomes. Although new students rarely arrive for training without preconceived ideas about other professions (Tunstall-Pedoe, Rink \& Hilton, 2009), nevertheless, training providers should find ways to establish collaborative learning, ideally early on in students' professional careers, to try to reduce the formation of intergroup stereotypes. Trainers should also be able to demonstrate how they facilitate IPE within their curricula (Williams et al., 2017).

\section{BACKGROUND AND AIMS}

Despite the imperative to incorporate IPE into curricula, and to evaluate its effectiveness, this can be difficult without formal university and healthcare provider strategies in place. Whiting at al. (2016) recommend that evaluators of IPE take a realistic position in their data collection, focusing primarily on attitudes and behaviour change, whereas others recommend that courses evaluate their IPE strategies using mixed methods, including a review of their impact on students in practice (Cahn et al., 2016). The initiative described in this paper sought to build on findings from previous studies attempting both approaches with student mental health nurses and trainee clinical psychologists (Priest et al., 2008; 2011), but this time in the context of child health care.

The importance of IPE has been highlighted in children's nursing contexts by students, mentors and university lecturers alike (Whiting et al., 2016), as on a day to day basis children's nurses interact with a wide range of professional groups such as speech and language therapists, social workers, psychologists and schoolteachers. Equally, IPE is crucial for clinical psychologists, as not only do they work directly into child teams, but also, their role in consultancy work demands an intimate awareness of other professional roles and functions. Children's nurses and clinical psychologists often need to work together; for example within complex family situations, and with conditions such as autism, ADHD, altered body image, gender identification, eating disorders, depression, anxiety, low selfesteem, self-harm and attempted suicide. The two groups are likely to come together within both in-patient and community mental health settings, including Child and Adolescent Mental Health Services, so it is crucial they can begin to learn the language of each other's profession (De Leon et al., 2014). 
However, many barriers to achieving successful IPE have been identified, particularly for psychologists. Within the UK, accreditation criteria for clinical psychology (BPS, 2019) require that 'opportunities for interprofessional learning are maximised' ( $p .28)$ and that 'working collaboratively and constructively with fellow psychologists and other colleagues and users of services' (p.20) is necessary. However, little detail is provided, and the required core competencies perhaps suggest more independent working through the assessmentformulation-intervention cycle and through the focus on organisational influence and leadership skills as well as on teaching and research. The work of Heath and Holmqvist, although undertaken in a Canadian context, has relevance internationally, suggesting that there are both structural as well as attitudinal barriers to the successful integration of psychologists into IPE. Structural barriers include geography, differing academic levels of study, and small group sizes compared to other professions. Attitudinal barriers include the assumption that psychologists, because of their training in human behaviour, are already skilled at collaboration, and thus do not need to participate in IPE. Such attitudinal barriers can form part of a hidden curriculum (Heath \& Holmqvist, 2017; Holmqvist, Button \& Heath, 2019), which underplays IPE and inhibits the development of interprofessional competencies. There is also some evidence to suggest that psychologists resist integrated working and are poor team players (Carpenter, Barnes \& Dickinson, 2006; Carpenter \& Dickinson, 2016;). In a child health context, arguably, the need for collaboration is even greater than in other settings. This study, therefore, set out to deliver an IPE initiative between these two groups of healthcare students, overcoming barriers particularly to the participation of psychologists, in relation to the following areas (Freeth et al., 2005):

1. Learners' reactions

2. Modifications of attitudes and perceptions

3. Acquisition of knowledge and skills

4. Change in behaviour and/or organisational practice

5. Benefits to patients and clients.

It was hoped that delivering an IPE programme with these two groups might ultimately help to increase awareness and break down any stereotyped ideas and communication barriers, by creating a better understanding of each other's roles and an insight into how, by working collaboratively, child health care may be delivered more effectively and in a more holistic and personalised way.

\section{METHODS}

\section{Data collection}

The IPE activities took place over three days in consecutive weeks. 17 child student nurses (CNs) and 15 trainee clinical psychologists (CPs), all in their third and final year of training, participated in the IPE initiative. IPE sessions were facilitated by a team of child nursing and clinical psychology lecturers, and included experiential and creative group work activities, problem-based learning (PBL) with clinical vignettes, and 'ask the expert' panels. Day 1 also included an experiential activity of relevance to all, namely a 'Theraplay' session ('a child and family therapy based on the natural patterns of playful, healthy interaction ... that is 
personal, physical, and fun'; www.theraplay.org). The variety of methods adopted was in keeping with Barr's (2003) assertion that relying on one method such as PBL is needlessly restrictive. It was also an attempt to evaluate IPE using mixed methods, including consideration of impact on students in practice (Cahn et al., 2016).

\section{Materials and activities}

Following introductions and ice-breaking exercises, and an introduction to IPE and the research project on Day 1, a questionnaire incorporating an adapted version of Parsell and Bligh's (1998) Readiness for Interprofessional Learning tool (RIPL) and a number of additional open questions was administered, to capture baseline data (R1). These qualitative questions considered previous experience of IPE; understanding of the other group's professional roles; and preparation for and expectations of the IPE initiative. A creative session then involved mixed groups of students producing a display of the professional groups' initial understanding of one another's roles and responsibilities. Day 1 continued with an introduction to a hypothetical case vignette (Figure 1) based on a teenager admitted to a children's ward following an episode of self-harm; this vignette was thought to be of relevance to both professional groups, as aside from the distress it can cause within families, self-harm is often met with stigma within health services (Doyle, Keogh and Morrissey, 2015). Within over-stretched ward-based provision, the psychological needs of a child who has self-harmed can easily be overlooked. The clinical vignette was devised collaboratively by psychology and children's nursing lecturers, attempting to include aspects that would be familiar to both groups of students.

\section{Insert Figure 1 around here}

Participants worked with this vignette in smaller mixed-profession groups. The groups' task was to discuss how they could effectively collaborate in the care of this young woman. They explored each other's professional perspectives surrounding issues that arose from the vignette, and discussed not only their acquisition of new knowledge, but also their experiences of working together and of sharing different viewpoints on a common task. The content was well received by the students and, indeed, seemed to spark debate. It was important that the students did not feel out of their depth and could actively participate which they appeared to do. 'Ask the expert' panels were introduced on Day 2, allowing participants to draw on the live expertise of qualified staff from both professional groups (mental health nurses, psychologists and children's nurses) to enhance their exploration of the clinical problem. Further time was included on Day 2 to work on the vignette.

Day 3 was largely comprised of the small groups sharing their learning with the whole group. Some creative methods were generated by the participants, such as role playing team meetings and the creation of a film. At this point, a second version of the questionnaire (R2) was administered, to assess any change over the time of the initiative in relation to Freeth et al.'s (2005) five key elements. A third version of the questionnaire was sent to all participants in May 2016 (R3), approximately 6 months after the sessions had ended, to assess any stability or change over time after return to practice. The CPs received their questionnaire face to face, while the child nurses received them electronically. 


\section{Data analysis}

The questionnaire was analysed by round [R1 = baseline administration; R2 = administration at the end of day 3 of the IPE initiative; R3 = 6 month follow up], and by profession. Quantitative data were analysed using SPSS and reported using descriptive statistics to illustrate any trends and changes over time. Qualitative data (open written comments from the questionnaire) were explored via thematic content analysis. Answers to questions were analysed individually for key words and phrases. Once a list of these had been created for each question the common words and phrases were examined and grouped by theme. All of the information from the qualitative section was entered onto NVivo software, which was used to produce a content analysis of the data, from which core themes were used to group the feedback from the two professional groups. The themes were then grouped into the five key areas of interest for this research (Freeth et al., 2005), with some overlapping questions and themes.

\section{Ethical considerations}

Ethical approval was granted by the University ethics panel. While participants were obliged to attend and participate in the IPE teaching, as part of their respective training courses, participation in the research project was optional. Only one participant did not wish to be included in the research project but participated fully in the sessions. All data remained confidential to the research team and data were anonymised via the use of code numbers.

\section{RESULTS}

There was considerable variation in attendance over the three sessions and some attrition, making an evaluation of trends over time difficult. On day 1, there were 15 CPs and 17 CNs taking part, giving a total of 32 baseline data questionnaires (R1) completed before the sessions began. This number fell to 26 completed questionnaires ( $11 \mathrm{CPs}$ and $15 \mathrm{CNs}$ ) on second administration immediately after the final IPE session (R2). By the final administration of the questionnaire, 6 months after the end of the sessions (R3), there were only $9 \mathrm{CP}$ responses and $3 \mathrm{CN}$ responses. At the start of the initiative, the participating children's nurses did not appear to have a clear understanding of a psychologist's role in a childcare context. Equally, while the role of a children's nurse may have been more widely understood, the clinical psychologists initially held largely stereotypical views as to what the role of a children's nurse entailed. The frequency of words used in the qualitative section of the questionnaire were detailed in word clouds (produced from the NVivo data) at times R1, $\mathrm{R} 2$ and R3. These word clouds represented the frequency of words used by participants in the written comments sections of the questionnaires, and highlight a change in emphasis in perceptions of role over time. At the start, the terms 'physical' $(2.6 \%)$ and 'mental' $(2.56 \%)$ were used to describe one another's roles, rather than psychological, which just had $1.28 \%$ frequency in the data, whereas by R3 the terms 'medical' and 'psychological' had equal frequency $(3.67 \%)$, showing a coming together of views and a reduction in initial stereotyped responses. 
The remainder of the results section addresses each of the five areas of interest (Freeth et al., 2005) from the combined qualitative and quantitative results.

\section{Learner's Reactions}

'Learners' reactions' provided a clear indication of how individuals felt about the sessions, the other members present, and those leading the sessions. Evidence for this outcome was drawn from questions about preparation, expectations, most helpful and least helpful aspects, and the challenges of participation.

From CPs, the main themes identified in the first administration of the questionnaire (R1) was 'little or no preparation' (7 occurrences). Common phrases were 'no preparation' and 'more detail'. However, questions around preparation were left blank 9 times for CNs, being the highest frequency type of answer, followed by 'timetable' occurring 4 times. A typical comment from a CP was:

'Some information given, more detail would have been useful to aid understanding of the day and aims' - CP9 R1.

By $R 2$, most CPs $(n=9)$ were satisfied with the preparation. Their written answers focused around having 'no expectations'. CNs were less certain about preparation, with 9 answering 'no' and 6 'yes' to a question about whether they felt prepared. Upon expansion of their answers, 'timetabling' came up 3 times, continuing from R1.

Regarding expectations of the IPE sessions, a theme for both CPs and CNs in R1 was 'teamwork', cited 4 times for CNs and 9 for CPs. This was not, however, carried over to R2 where there was a split in opinion. CPs had a 'positive experience' 4 times with 'not helpful' mentioned 3 times. 5 answers for CPs were blank. CNs stating they were 'unsure of expectations' appeared 5 times. An example of two CPs themes and one from CNs are below:
'Interesting experience to work with medically minded colleagues prompted wider discussions about wider issues (e.g. stigma)' - CP13 R2
'I thought it would be unhelpful, and it turned out to be neither helpful or unhelpful' - CP8 R2
'Wasn't sure what to expect' - CN32 R2

For the remaining questions around helpful and unhelpful aspects and challenges, the main themes identified from both groups was 'discussion', occurring 13 times between both CPs and $\mathrm{CNs}$ and presented in a positive light.

'Talking to psychology students about what they do' - CN27 R2

'I found it interesting to discuss the physical impacts of overdoses + ward environment' - CP5 R2

By R3, the theme of 'discussion' no longer appears. On the other hand, both 'defensiveness' and 'co-operation' were identified as the main challenges, mentioned 24 times overall, 14 
times by CPs and 10 times by CNs. CNs also spoke about 'location and logistics' in attending sessions as a challenge, mentioning this theme 11 times.

'Defensiveness and splitting 'us + them' has prevented some helpful conversations developing' - CP15 R2

'Challenge with some individuals in groups being less receptive of our role + challenges within this. Unhappy that all 3 sessions are in [City]. Would be good to have at least one in [Other town]...' - CN29 R2

This is important to consider for future sessions because there was some uncertainty before the session around its content and some of the organisational aspects, with CNs not seeing the session appear on their timetable. This could cause anxiety and some missing the sessions if there is significant travel involved.

Qs10 and 19 from the adapted RIPL (Parsell and Bligh, 1998) provided evidence for 'learners' reactions'. Q 10 gives mixed results, with CPs showing an initial disagreement with the statement 'It is a waste of time learning with other health professionals', followed by greater agreement by R3. The reverse is true for the $\mathrm{CNs}$ who had become more positive about IPE by the end of the 6 month period. The same findings are reflected in Q19, with CNs showing an initial, if small, increase in agreement with the statement that 'It is not necessary for trainee health professionals to learn together', and the reverse for the CPS. However, the R3 results from CNs should be interpreted with caution as only 2 questionnaires were returned from this group.

\section{Modification of Attitudes and Perceptions}

'Modification of attitudes and perceptions' was identified as any change being a key measure of the success of the IPE sessions. Questions informing this element included those around similarities and differences in roles.

From both sets of participants, working with 'family and children' was identified as a similar theme, appearing 8 times in the CPs answers and 9 times in CNs. 'Teamwork and communication' was identified 8 times by the CPs as a similarity. CNs mentioned 'mental health' as a similarity of their jobs 7 times, which did not appear in any CP answer.

'Working with children and families' - CN27 R1

'... The communication skills needed and creativity of approach when interacting with children' - CP2/11 R1

Looking at the differences between professions, the main theme was the difference between 'physical and mental health', occurring 25 times between the groups. The most common words associated with this theme were 'clinical skills' and 'medical'.

'Children's nurses = physical health. $C P$ 's $=$ mental health' $-C P 2 / 11 R 1$

CPs also mentioned 'care and compassion' as a similarity in 5 answers in R2. The main differences in R2 were again 'medical vs mental health' occurring a total of 19 times 
between CPs and CNs. Another theme from the CNs' answers was 'time constraints', mentioned as a difference in 5 answers, often referring to CPs' apparent greater reflection time to process complicated problems.

'They get time to reflect' - CN33 R2

Q9 and Q11 from the RIPL best support the element of 'Modification of Attitudes and Perceptions'. The average scores in response to the statement 'Trainee health professionals need to trust and respect each other' rose for both CNs and CPs from before sessions to after sessions. 'Defensiveness and co-operation' may explain why there is a rise here from before the sessions to afterwards, with both groups of professionals realising the importance of being on the same page professionally. There was a positive movement, with scores for the statement 'I do not have a clear idea of how clinical psychologists and children's nurses can work together' falling for both CPs and CNs. This improvement supports the theme of 'understanding of roles' and the reduction of stereotyped views.

\section{Acquisition of skills and knowledge}

'Acquisition of skills and knowledge' was an important element to examine, because one of the aims of IPE is to build the skills and knowledge of participants through learning with each other. There were no questions asking about acquisition of skills and knowledge based on IPE in R1. In R2, questions used to analyse skills and knowledge acquisition were around contributions of the IPE sessions to understanding the others' roles; new awareness of the other professionals' roles; and new learning that will help them in the future. The main theme that stood out was 'understanding of roles', appearing a total of 40 times from both CPs and CNs.

'Greater knowledge + understanding of the nursing role, differences and similarities of roles, leadership skills, greater understanding/awareness of NHS demands + priorities in each role' - CP15 R2

Another theme from CPs was 'processes and working together', being mentioned 17 times. Common words in this theme are 'demands' and 'leadership'.

'How to try and manage difficult group dynamics. Awareness of how I can be put in a leadership role which isn't always helpful' - CP4 R2

Many respondents answered with a general 'understanding' tone; however, there were few common themes around specific skills learnt. Responses to the statement 'Shared learning with other trainee health professionals will increase my ability to understand clinical problems' showed a general increase in agreement from CNs, but a general decrease from CPs.

\section{Change in behaviour and organisational practice}

While this study was unable to provide any observational data to support this element, evidence of a 'Change of behaviour and change of organisational practice' would indicate a 
change in perception of how professionals work together, with any positive changes identified being a good indicator of the usefulness of IPE when applied to practice. There were no questions about changes in behaviour in R1. In R2 and R3, answers around questioning beliefs and assumptions were used to indicate that a change of behaviour had taken place.

The main theme from CPs answers was 'little change', with this theme appearing 8 times.

'I always do this anyway - I'm not resolute in my opinions so l'd say this re-enforces that' $-C P 16 R 2$

$\mathrm{CNs}$, however, had more positive answers, with the theme 'openness to ideas and change' appearing 8 times. This theme again lacks precision of what changes they are considering.

'Open to other profession, in their ideas + thoughts that could help + influence ours' CN29 R2

While respondents found it hard to pinpoint exact changes that they would be implementing in their practice, positive answers given in other sections suggest that any changes are likely to be made subconsciously or unconsciously.

Q15 of the adapted RIPL specifically evaluated change in behaviour. There was little evidence of change from CPs. This suggests that the IPE sessions has not provoked a possible change in behaviour to improve their team work. CNs appear to have shown more signs of taking on board teamwork improvements.

\section{Benefits to patients}

There were a number of respondents who said that a common skill was in putting the child and family at the centre of their work. Questions used to analyse this area were around new learning identified as a result of the IPE that signal a benefit to patients/service users. 'Working together' was a recurring theme for this question, being mentioned 8 times by $\mathrm{CPs}$. This theme is in relation to working with CNs which, if there are improvements in cooperation of staff, will result in improved care for patients.

'How I can use my role to facilitate learning + engagement, particularly with people who may have different ideas' - CP5 R2

CNs also described a similar theme to CPs, with 'teamwork' appearing 3 times. CNs gave answers of 'mental health' 4 times, and in particular, self-harm was mentioned twice. This shows a direct lesson learnt by CNs from CPs that will potentially benefit patients.

'Not to stigmatise children who self-harm' 


\section{DISCUSSION}

This study set out to build on previous local initiatives between mental health nurses and clinical psychologists (Priest et al., 2008; 2011), but this time focusing on health professionals (children's nurses and psychologists in training) working collaboratively within child mental healthcare contexts. Specifically, it set out to explore and evaluate any changes in the following areas: Learners' reactions; Modifications of attitudes and perceptions; Acquisition of knowledge and skills; Change in behaviour and/or organisational practice; and Benefits to patients and clients (Freeth et al., 2005). The IPE sessions encouraged good conversations about roles that appear to have left a lasting impression on participants. This was positively reflected on as 'raising awareness of the differences and similarities of roles and a greater understanding of NHS demands and priorities.' This is an indicator of the usefulness of IPE, as lack of awareness of other professional roles or the presence of stereotyped views may hinder referral to appropriate agencies. It may also cause duplication of work; hence a better understanding of a specific professional role may assist in time management.

The study successfully facilitated conversations about wider issues related to the clinical vignette (such as self-harm and hospital ward environments) and highlighted key areas of shared working, such as families, teamwork, communication and mental health. However, the 'nurses = medical' versus 'psychologists = mental health' split persisted as a key positional belief throughout, with neither profession initially appearing to consider the potential combination of these positions, nor how by combining diverse skills, the overall outcome for the child and family may be a more positive one. Encouragingly, however, it seems that over time, the professional differences reduced, in terms of word usage in feedback, as the students became more aware of the others' specific roles. The shift in emphasis in the use of words from 'working', through 'role' to 'time' seems to show a developing empathic position of one another's roles - as professions work together, the notion that one profession is working harder than the other shifts to a more contextualised understanding of time constraints and pressures upon individuals, rather than about specialist professional skills.

CNs were generally more positive than CPs in their agreement and disagreement with questionnaire statements. They started from a more positive point of view, and their attitudes and perceptions improved over time, whereas CPs had maintained or returned to initial levels of agreement by R3. CNs talked about the constraints upon their time and felt, with some suggestion of envy, that they did not have the opportunity to 'reflect' as much as the CPs. Nonetheless they were more positive overall about the IPE sessions. Conversely, CPs were not particularly receptive when questioned about their beliefs, assumptions and familiar ways of working, whereas the CNs appeared to be more 'open to ideas and change'. These perceptions need further testing.

Unlike earlier initiatives (Priest et al, 2008; 2011), the sometimes tricky element of bringing together students at very different academic levels of study (postgraduate doctorate level for the CPs; undergraduate Batchelors level for the CNs) did not seem to be a factor of concern for these participants; however, it may have underpinned some of the defensiveness and divergence in views over time, and needs further exploration. 
As with previous initiatives (Priest et al., 2008; 2011), greater attention is needed to be paid to the preparation of students in advance of IPE delivery, so that they have a greater understanding of the purpose, aims and objectives of the sessions. This was particularly the case for CPs, despite them being more aware of the IPE sessions than CNs through having some advance information on their timetables. Perhaps the $\mathrm{CNs}$, being more 'open to ideas', were happier to 'go with the flow' despite having limited preparation and uncertain expectations.

The main challenges and areas for improvement appear to be 'logistics and locations', with CPs finding the time in their final year could have been spent more wisely on their dissertations, and CNs having to travel a long way and having trouble parking on arrival. The CNs' apparent greater responsiveness towards the sessions, compared with the CPs, may be associated with the timing of sessions in the overall curriculum, and this requires revisiting. Overall, greater attention is needed to the fundamental practical elements of location, travel logistics, and parking. Despite the careful inclusion of 'pleasant' activities of relevance to all, such as the experiential 'Theraplay' session and a shared lunch on the final day, such practical irritations appeared to get in the way of full involvement and enjoyment of the sessions.

Interprofessional education is not always a routine component of health professional education, and that may be associated with the many challenges of both the conducting and the sustainability of IPE. There needs to be a cultural change away from uniprofessional practice and training, and greater executive support to embed IPE within educational settings. Barr et al. (2014) suggest that service user engagement within the development and implementation of IPE should be considered, but this would bring additional logistical and financial challenges. Time is limited and academic staff are overwhelmed with managing their own specific professional groups - to incorporate other groups within this can be, understandably, less of a priority. One possible solution may be to develop a programmatic approach to IPE - to develop a framework that has been designed to include IPE activities across the entire curriculum in a strategic, structured manner. The feedback from the participating students in this study highlighted that ethics teaching may have been a good starting point. This may be designed and led by a specific IPE team from all health professional programmes, with sub groups formed to work upon specific objectives. A steering group would oversee activity, planning well in advance with administrative support - starting small and building incrementally. Subsequently, IPE would become an established part of a curriculum rather than an 'ad hoc' activity slotted in when time allows. Teodorczuk et al. (2016) also suggest that some of the challenges may be overcome by careful planning and consideration of the learning outcomes of all of the students involved. The work of Stephen et al. (2017) in the UK in mapping common outcomes from a range of professional bodies provides a helpful starting point. It is important also to identify and integrate appropriate means of evaluating the impact of IPE; the work of Batteson and Garber (2019) in developing and validating an IPE measurement tool holds promise in this respect. 


\section{LIMITATIONS}

One of the key limitations in this study was the variation in numbers of participants attending the three IPE sessions and the high attrition rate at follow up, making it difficult to follow response trends. Comments from students attending two (or only one) of the sessions had to be interpreted with caution as they did not have the full IPE experience. There is also a risk of response bias from CNs in particular, because of the method in which the final R3 questionnaire was administered (via email) and the fact that they had effectively completed academic training and moved into final consolidation clinical placements. For these reasons, themes from these results are used sparingly and interpretation of results should be cautiously made, particularly those from the quantitative part of the $\mathrm{CN}$ questionnaires, where in fact only 2 child nurses gave valid results.

\section{CONCLUSIONS}

Overall, the evidence from this study suggests the IPE sessions were effective in meeting some of their aims, with the main benefits and strongest themes being 'understanding roles' and 'teamwork and discussion'. As with most classroom-based IPE activities, the greatest impact appeared to be in the areas of 'modification of attitudes and perceptions' and 'acquisition of skills and knowledge'. Participants appeared to find it useful to work in mixed groups and to discuss working in the child mental health care context; however, 'defensiveness' was a key theme, demonstrating that each group had to explain and defend their own roles with some passion. The somewhat fixed positional beliefs, at least initially, about medical versus psychological roles are in many ways realistic, but encouragingly, these appeared to shift over the time span of the project. This suggests that stereotypical views of what each profession brings have changed, with by the third questionnaire words such as appreciation, opportunity, empathy and awareness being used more frequently in the feedback. Further exploration of these differences is needed, and opportunities to do so built into future sessions.

Future initiatives also need to identify means of reducing attrition, so as to track trends more confidently. A subsequent run of this project in the following year addressed some of the practical and logistical challenges with some success, and attrition was noticeably reduced. Learning from delivery and evaluation of each programme will continually be used to improve and enhance the IPE experience for subsequent cohorts.

\section{ACKNOWLEDGEMENTS}

This work was supported financially by Staffordshire University Vice Chancellor's Small Research Grants Scheme 


\section{REFERENCES}

Barr, H. (2003), "Ensuring quality in interprofessional education", CAIPE Bulletin Vol 22, pp. $1-3$.

Barr, H., Helme, M., and D'Avary, L. (2014), "Review of interprofessional education in the United Kingdom 1997-2013". http://caipe.org.uk/publications.html.

BPS (2019), Standards for the Accreditation of Doctoral Programmes in Clinical Psychology. Leicester: British Psychological Society.

Batteson, T. and Garber, S. (2019), "Assessing constructs underlying interprofessional competencies through the design of a new measure of interprofessional education", Journal of Interprofessional Education and Practice, Vol 16. DOI 10.1016/j.xjep.2018.08.004

Cahn, P., Bzowyckyj, A., Collins, L., Dow, A., Goodell, K. et al. (2016), “A design thinking approach to evaluating interprofessional education", Journal of Interprofessional Care, Vol 30 No 3, pp.378-380.

\footnotetext{
Carpenter, J. and Dickinson, C. (2016), "Understanding interpofessional education as an intergroup encounter: The use of contact theory in programme planning. Journal of Interprofessional Care, Vol 30, No 1, pp. 103-108.
}

Carpenter, J., Barnes, D., and Dickinson, C. (2006), "Outcomes of interprofessional education for Community Mental Health Services in England: The longitudinal evaluation of a postgraduate programme", Journal of Interprofessional Care, Vol 20, pp. 145-161.

DeLeon, P. H., Sells, J. R., Cassidy, O., Waters, A. J., and Kasper, C. E. (2015), "Health policy: Timely and interdisciplinary", Training and Education in Professional Psychology, Vol 9 No 2, pp. 121-127. http://dx.doi.org/10.1037/tep0000077

Doyle, L., Keogh, B. and Morrissey, J. (2015), Working with Self-harm and Suicidal Behaviour, Palgrave, London.

Freeth D., Hammick M., Reeves S., Koppel I. and Barr H. (2005), Effective Interprofessional Education. Development, Delivery and Evaluation, Blackwell, Oxford.

Heath, O and Holmqvist, M. (2017), Developing Interprofessional Competencies in Professional Psychology: A Practical Guide. New York, Momentum Press.

Holmqvist, M., Button, P., and Heath, O. (2019), "Together we stand: The imperative for interprofessional education in professional psychology training", Canadian Psychology, Vol 60, No 4, pp. 255-264. 
Parsell, G. and Bligh, J. (1999), "The development of a questionnaire to assess the readiness of health care students for interprofessional learning", Medical Education Vol 33, pp. 95100.

Priest, H., Roberts, P., Dent, H., Blincoe, C., Lawton, D. and Armstrong, C. (2008), "Interprofessional education and working in mental health: In search of the evidence base", Journal of Nursing Management, Vol 16, pp. 474-485.

Priest, H., Roberts, P., Dent. H., Hunt, T., Weston, D., Chell, A., Blincoe, C. and Armstrong, A., (2011), "Preparing for collaborative working in mental health: An interprofessional education project with clinical psychology trainees and nursing students", The Journal of Mental Health Training, Education and Practice, Vol 6 No 1, pp. 474-485. DOI: 10.1108/17556221111136161.

Stephen, K., Howden, S., Mires, G., Rowe, I., Lafferty, N., Arnold, A., and Strath, A. (2017), "Toward interprofessional learning and education: Mapping common outcomes for prequalifying healthcare professional programs in the United Kingdom", Medical Teacher, Vol 39 No 7, pp.720-744. DOI: 10.1080/0142159X.2017.1309372

Teodorczuk, A., Khoo, T.K., Morrissey, S., and Rogers, G. (2016), “Developing interprofessional education: Putting theory into practice", The Clinical Teacher, Vol 13, pp. 7-12.

\section{Tunstall-Pedoe, S., Rink, E., and Hilton, S. (2003). "Student attitudes to undergraduate interprofessional education", Journal of Interprofessional Care, Vol 17, No 2, pp. 161- 172. DOI: $10.1080 / 1356182031000081768$}

Whiting, L., Caldwell, C., and Akers, E. (2016), "An examination of interprofessional education in a pre-registration children's nursing course", Nursing Children and Young People, Vol 28 No 6, pp. 22-27. https://doi.org/10.7748/ncyp.2016.e747

Williams, B., Beovich, B., Ross, L., Wright, C., and Ilic, D. (2017), "Self-efficacy perceptions of interprofessional education and practice in undergraduate healthcare students", Journal of Interprofessional Care, Vol 31 No 3, pp. 335 -341.

http://dx.doi.org/10.1080/13561820.2017.1286637 
Emma, aged 15, has been admitted for assessment to a paediatric ward following an attempted overdose with paracetamol.

Emma lives with her mother Karen, her sister Chloe (aged 17), and brother Harry (aged 10). Emma's parents separated seven years ago, after which time Karen and the children moved to a new home. Karen is employed full time and there are no financial problems. Emma, Chloe and Harry see their father Phil regularly, but Emma has recently said she would rather stay at home with her Mum.

Karen's pregnancy with Emma was full term and there were no particular difficulties but there were problems with her delivery; she needed to be resuscitated and she was kept in an incubator for two days. Nevertheless, Emma was described as a happy cheerful baby, who was generally contented. She was slow in achieving some of her developmental milestones; she walked at 18 months, talked at about 30 months, and was toilet trained at 4 years. Emma attended nursery and primary school, where she settled well; there was no significant separation anxiety on starting nursery or school. She currently attends High School and is in year 10 . She attends regularly but is struggling with her GCSE course work. She has a small group of friends and enjoys music.

There is no known history of mental illness in the family. However, Emma has a history of self-harm that started when she was 12 , shortly after she started at High school. She was unable to identify any particular triggers, but had started menstruating and her weight increased to 65 kilograms (height $160 \mathrm{~cm}$ ). She has been superficially cutting her arms and legs since that time. She does not like physical education lessons as she is embarrassed about the scars on her legs, and this causes ongoing anxieties. She told her friend Hannah about her self-harm and felt supported by her; however she was teased by another friend, Katie, making the relationship difficult and resulting in an increase in self harm. Emma recently split up with her boyfriend after being together for a year.

On the ward, Emma appears quiet and withdrawn. She does not maintain eye contact and is tearful and reluctant to talk.

Figure 1: Case vignette 